\title{
ПРАВОВОЙ РЕЖИМ НЕДРОПОЛЬЗОВАНИЯ В РОССИИ (ТЕОРЕТИЧЕСКОЕ МОДЕЛИРОВАНИЕ)
}

\section{LEGAL REGIME OF SUBSURFACE USE IN RUSSIA (THEORETICAL MODELING)}

O. Efimova

Summary. The legal reality of our time consists of an informational set of civilizational paradigms that affect the consciousness of young scientists and practitioners of law in one way or another. Some of them remain unnoticed in the General digital stream, while others find a response, generate stereotypes and become a source of legal knowledge for many years to come. Industrial development of the subsurface use industry requires adequate development of its legislative regulation. The successful application of various legal instruments to improve legislation contributes to a more reliable assessment of existing realities. This article presents a theoretical model of the legal regime of subsurface use, revealing its public component as an element of applied measures to improve the regulatory framework and increase the attractiveness of the industry for private investment.

Keywords: subsoil; legal model; legal regime, method of legal regulation, objects of civil rights, subject of legal regulation.

\author{
Ефимова Олеся Константиновна \\ Литигатор юридической компании, ООО «АПР \\ «Викон»; аспирант, Тюменский государственный \\ университет \\ aprvicon@yandex.ru
}

Аннотация. Правовая реальность современности соткана из информационного множества цивилистических парадигм, так или иначе влияющих на умы молодых ученых, юристов практиков. Какие-то из них остаются незамеченными в общем цифровом потоке, какие-то находят отклик, порождают стереотипы и становятся источником юридического знания на долгие годы. Индустриальное развитие отрасли недропользования предполагает адекватное развитие законодательного её регулирования. Успешное применение многообразия правовых средств для целей совершенствования законодательства во многом способствует более достоверной оценке существующих реалий. В данной статье представляется теоретическая модель правового режима недропользования, выявляющая его публичную составляющую как элемент прикладного применения мер совершенствования законодательной базы и повышения привлекательности отрасли для частных инвестиции.

Ключевые слова: недра; правовая модель; правовой режим, метод правового регулирования, объекты гражданских прав, предмет правового регулирования.

ственный геологический фонд недр сведения о запасах полезных ископаемых позволяют констатировать ухудшение качества добываемого сырья и усложнение минерально-сырьевой базы. Запасы полезных ископаемых становиться всё труднее извлекать, о чем говорит глубина сооружаемых в последние годы поисковых и разведочных скважин. Понимание данной проблематики отражает, в первую очередь, принятая год назад Правительством Российской Федерации «стратегия развития минерально-сырьевой базы страны» [1]. Согласно которой основным приоритетом развития недропользования является формирование баланса объемов внутреннего потребления минерального сырья, его экспорта и вынужденного импорта, достигаемого путем прироста запасов - своевременного воспроизводства и рационального использования полезных ископаемых.

Перспективным источником и реализатором задачи прироста запасов (освоения недр с использованием передовых технологий) в принятой стратегии выступает новый участник - частные инвестиции. Для появления которых в изначально публичной сфере отсутствуют правовые основания. Что порождает государственную 
необходимость такие основания создать. Именно этому посвящен $\mathrm{V}$ разделе самой Стратегии, предусматривающий формирование условий для стабильного «обеспечения минеральным сырьем социально-экономического развития государства и поддержания достаточного уровня экономической и энергетической безопасности Российской Федерации» [2].

В контексте задачи создания передовой законодательной базы и реализации активной политики привлечения инвестиций [3], стратегия развития минерально-сырьевой базы России в начальный период формирования (ближайшие 5 лет) ориентирована на создание и развитие важнейших экономических, административных и правовых основ, направленных на увеличение инвестиционной активности в результате повышения экономического интереса к отрасли и недропользованию (вовлечение частных средств).

Изменение государственного подхода и стремительность реформирования права, проявленная в 20192020 годах, детерминировали поиски цивилистов, в области определения оптимальных путей решения задачи через нормотворчество.

Исследование недропользования с точки зрения цивилистики осложнено множественными пересечениями с иными отраслями права. Поэтому выбор правового инструментария вопрос концептуальный, требующий построения теоретической модели существующего правового режима недропользования.

Представители современной юридической науки достаточно часто прибегают к определению характеристик правовой модели как средства познания [4].

В данной публикации, используем, наиболее ёмкое из них, определение правовой модели, данное В.С. Плетниковым и М.С. Плетниковой в 2011 году [5] в последствии качественно уточненное в 2016 году [6] «интеллектуально-волевое описание (образ явления), В достаточной степени повторяющий существенные свойства моделируемого явления, сформировавшийся под влиянием всей совокупности объективных и субъективных факторов общественного развития».

Примем как данность, что любая модель является значительно упрощенным вариантом своего оригинала. Говоря же о правовой модели, мы не предполагаем наличие оригинала, воспринимая эмпирически характеристики правового режима, требующиеся для построения его теоретической модели.

В методологии права известны три основные функции теоретического моделирования - объяснительная (дескриптивная), прогнозная, критериальная. Используем одну из них (дескриптивную), для создания представления о правовых реалиях исследуемой отрасли (недропользования) - построения реальной модели правового режима недропользования.

Цель построения правовой модели требует выявления содержания правовых явлений, синтезирующих комплекс правовых средств, для построения модели правового режима недропользовании через призму механизмов регулирования и состава правоотношения. Алгоритм достижения цели должен способствовать формированию представления о правовом режиме недропользования, в его статичном понимании источниками права. Для чего выделим прикладной инструментарий, позволяющий идентифицировать недропользование в совокупной массе правовых явлений общественной жизни:

- способ, тип, вид и метод правового регулирования, охарактеризуют совокупность признаков отнесения исследуемого явления к определенной совокупности отраслей права по центральному субъекту (частное, публичное);

- предмет правового регулирования позволит условно выделить ту часть общественных отношений, на которую направленно нормативное (регулирующее) воздействие;

- акты реализации прав и обязанностей как показатель функциональности модели правового режима недропользования.

Недропользование [7] как общее понятие, объединяющее в себе совокупность правомочий направленных на реализацию разрешенных видов пользования природными ресурсами, нередко рассматривается как отдельная подотрасль права [8], с множество вовлеченных в нее объектов.

Для построения модели правового режима классифицируем объекты гражданских прав в составе предмета правового регулирования.

Реализуя задачу системной классификации объектов в данном исследовании приводится присущий только отрасли недропользования перечень объектов, выделяются группы объектов по материальным и поведенческим (нематериальным) признакам; по оборотоспособности (полностью оборотоспособные, ограниченные в обороте, изъятые из оборота); по характеру связи с землей (движимые, недвижимые); по способности сохранять потребительские свойства в процессе эксплуатации (потребления); по способам юридической индивидуализации (индивидуально-определённые, родовые); по назначению (главные, относимые; средства производства, предметы потребления). 
Таблица 1. Модель правового режима недропользования (инструментарий построения модели механизмы правового регулирования)

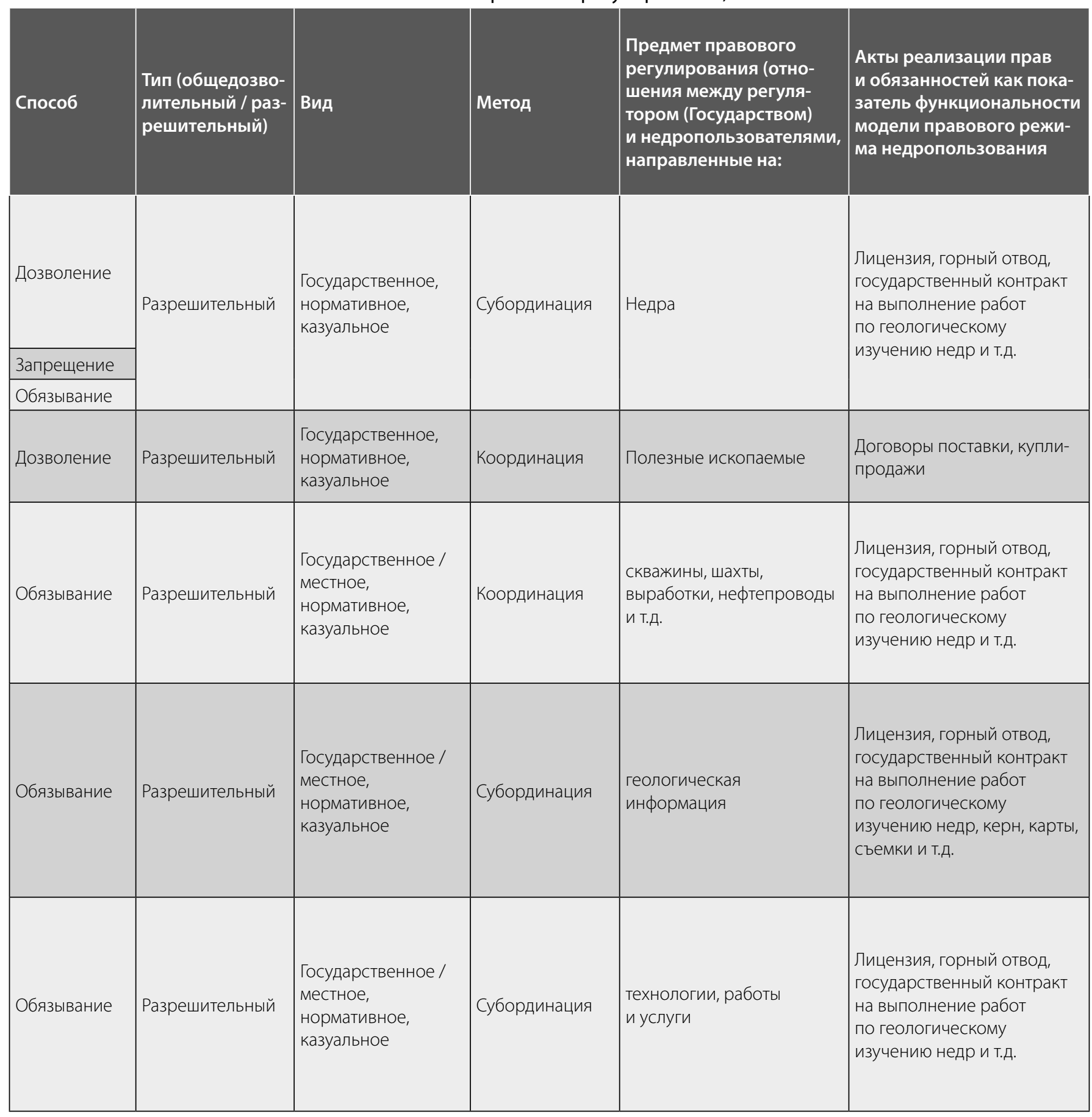

Выделим следующие классы объектов гражданских прав характерные только для исследуемой отрасли недропользовании:

Первый класс - недра. Объекты недвижимые по природе, изъятые из оборота (государственная собственность, образующая государственный фонд недр) [9] или ограниченные в обороте (предоставляемые госу- дарством на определенный временной период на основании специального разрешения - лицензии) [10], природный ресурс, средство производства.

Второй класс - полезные ископаемые (ресурсы недр). Продукция (товар), предмет потребления, ограниченные в обороте на этапе первоначального приобретения права собственности (извлечение из недр 
и перемещение, осуществляется в соответствии с установленными правилами (условиями добычи), объемы добычи фиксируются государством и т.д.) [11] и оборотоспособные в последующем (свободно передаваемые).

Третий класс - недвижимое имущество, созданное и используемое при недропользовании. Отличительной особенности этого класса объектов в недропользования является создание потребляемых недвижимых объектов - сооружений предназначенных для конкретной цели и юридически ликвидируемых после её достижения, но фактически продолжающих своё существование в измененном виде [12].

Четвёртый класс - информация, получаемая в процессе изучения и использования ресурсов недр. Материальные и нематериальные, не потребляемые (потребительские качества не изменяются в процессе использования) объекты. Следуя принципу объективности исследования, нужно указать, что и, исследователи, и практики, расходятся во мнениях об обоснованности отнесения информации к объектам гражданских прав: сторонники закрепления информации в общем, и геологической информации в частности, в ст. 128 ГК РФ как полноценного объекта гражданских прав, исходят из необходимости четкой регламентации оборота геологической информации и защиты прав обладателя такой информации как собственника, отсюда возможность использовать договорной инструментарий при сделках с геологической информацией: аренда геологической информации, в том числе финансовая аренда (лизинг), купля-продажа, мена и т.д. Противники указывают на диспозитивность законодательной нормы, позволяющую отнести информацию к «иным» объектам гражданских прав.

Пятый класс - работы, выполняемые при пользовании недрами и технологии геологического изучения, разведки и добычи полезных ископаемых. В исследуемой отрасли данный объект подлежит выделению в отдельный класс, исходя из понимания, что виды недропользования, предусмотренные законодателем, предопределяют статус работ - ради самих работ, а не ради результата. Именно в недропользовании поведенческая группа имущественных действий характеризует поиск полезных ископаемых, их разведку, под чем понимается огромный функционал, существующий в плоскостях гражданского и природоресурсного права.

Реализация механизма построения модели правового режима недропользования представляется следующей (см. таблицу 1).

Представленная правовая модель позволяет констатировать преобладание в её структуре элементов, присущих публичным отраслям права, основные принципы цивилистических догм нивелируются методом правового регулирования.

Исследование правового режима недропользования приведенное в данной работе, призвано сформировать модель правового режима для визуализации возможной зоны ослабления регулирующей роли участия публичных образований, поиска возможности увеличения степени предпринимательских свобод и потенциальной правовой ниши для новых рыночных форм сотрудничества государства и бизнеса, способствующих стабильному и рациональному использованию природных богатств страны на её благо.

Правовые категории в этой сфере все еще имеют размытые контуры, чем заслуживают пристального внимания и изучения. Учитывая, что имущественные отношения, опосредующие право пользования недрами, развиваются, в то время как в законодательстве и практике отсутствует единое понимание соответствующих вопросов, освещение фундаментальных проблем права пользования недрами представляет большой научный и практический интерес для отечественной правовой науки.

\section{ЛИТЕРАТУРА}

1. Распоряжение Правительства РФ от 22.12.2018 N2914-р «06 утверждении Стратегии развития минерально-сырьевой базы Российской Федерации до 2035 года» // Режим доступа: http://www.pravo.gov.ru/laws/acts/3/50574952451088.html (дата обращения: 15.11.2019).

2. Государственный доклад о состоянии и использовании минерально-сырьевых ресурсов Российской Федерации в 2018 году // Министерство природных ресурсов и экологии Российской Федерации // Официальный сайт ФГБУ «Всероссийский научно-исследовательский институт минерального сырья им. Н. М. Федоровского» // Режим доступа: http://vims-geo.ru/documents/402/Gosdoklad_2018.pdf (дата обращения: 01.03 .2020 г.)

3. Послание Президента Российской Федерации Федеральному Собранию Российской Федерации от 1 марта 2018 г. // Режим доступа: http://www.consultant. ru/document/cons_doc_LAW_291976 (дата обращения: 15.08.2019).

4. Безруков А.С. 2008. Правовая модель как инструмент юридической науки и практики: дис. ... канд. юрид. наук. Владимир. 151 с.

5. Плетникова М.С., Плетников В.С. 2011. Конституционно-правовые основы разграничения бюджетных полномочий между органами государственной власти субъектов и органами местного самоуправления в Российской Федерации: моногр. Екатеринбург: УрЮИ МВД России. 141 с.

6. Плетников В.С. 2016. Понятие и виды моделей в современной отечественной юриспруденции: теоретико-правовое исследование. Наужный ежегодник Института философии и права Уральского отделения Российской академии наук. Том 16. Вып. 2, с. 121-135. 
7. Национальный стандарта РФ «Государственная система обеспечения единства измерений. Метрологическое обеспечение работ по геологическому изучению, использованию и охране недр в Российской Федерации. Основные положения. ГОСТ Р 8.645-2008», утв. Приказом Ростехрегулирования от 15 октября 2008 г. N259-ст // // Режим доступа: http://www.consultant.ru (дата обращения: 10.11.2019).

8. «Нормы, регулирующие отношения по поводу использования и охраны отдельных природных объектов, объединяются в подотрасли земельного, водного, горного, лесного фаунистического, атмосферного и заповедного права». См.: Экологическое право: Учебник / Отв. ред. Г. Е. Быстров, Н. Г. Жаворонкова, И. 0. Краснова. М., 2007. С. 37.

9. Недра в границах территории Российской Федерации, включая подземное пространство и содержащиеся в недрах полезные ископаемые, энергетические и иные ресурсы, являются государственной собственностью. Вопросы владения, пользования и распоряжения недрами находятся в совместном ведении Российской Федерации и субъектов Российской Федерации — ст. 1.2. Закон РФ от 21.02.1992 N2395-1 (ред. от 27.12.2019) «0 недрах» (с изм. и доп., вступ. в силу с 03.02.2020).

10. Участки недр не могут быть предметом купли, продажи, дарения, наследования, вклада, залога или отчуждаться в иной форме. Права пользования недрами могут отчуждаться или переходить от одного лица к другому в той мере, в какой их оборот допускается федеральными законами - там же.

11. Закон РФ от 21.02.1992 N2395-1 (ред. от 27.12.2019) «0 недрах» (с изм. и доп., вступ. в силу с 03.02.2020)

12. Проект Федерального закона «0 внесении изменений в Закон Российской Федерации «0 недрах» и Федеральный закон «0 приватизации государственного и муниципального имущества» в части определения правового режима недвижимого горного имущества» (подготовлен Минприроды России) (не внесен В ГД ФС РФ, текст по состоянию на 12.05.2018)
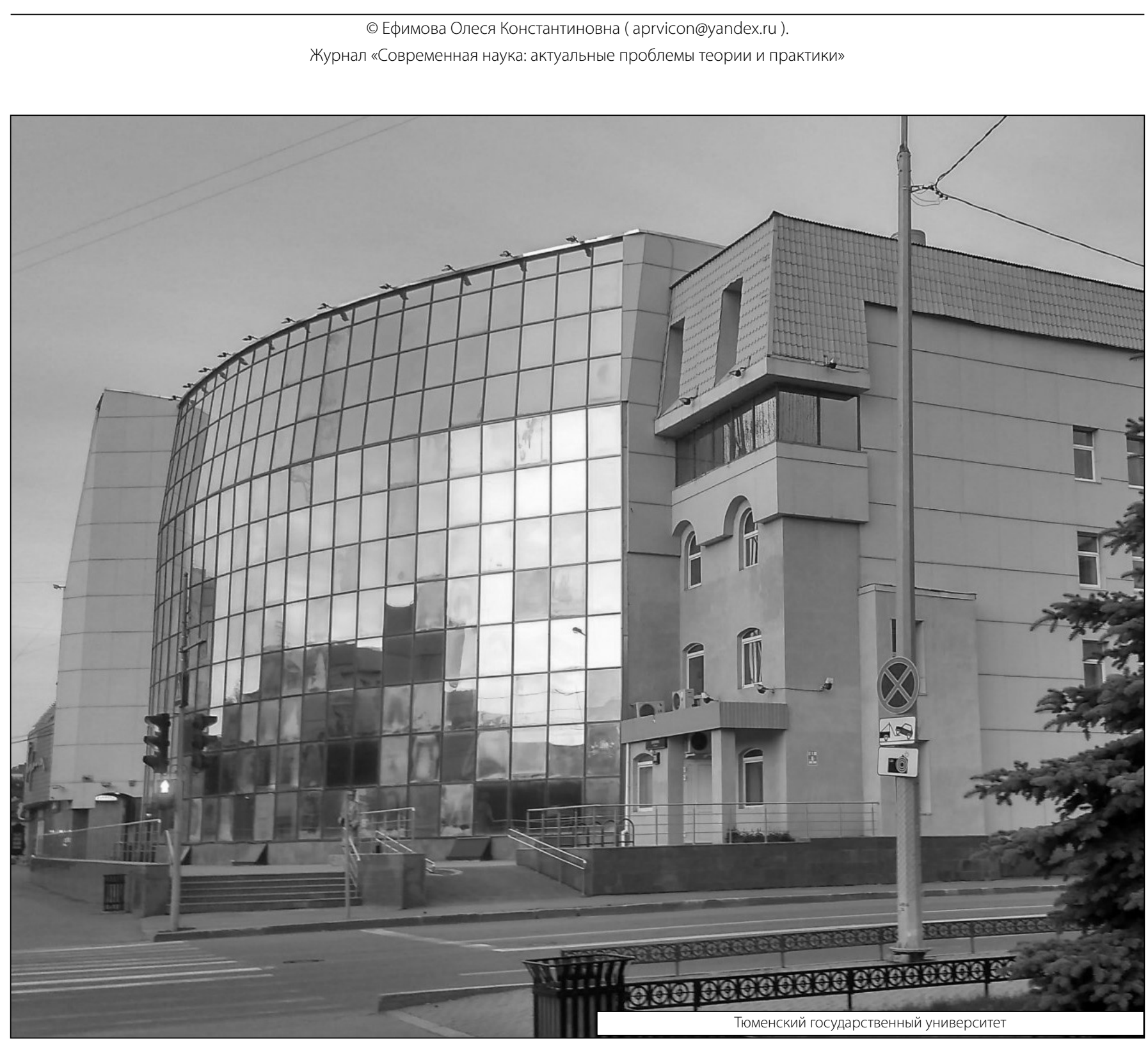